\title{
Social inequality and common mental disorders
} Desigualdade social e transtornos mentais comuns

\author{
Letícia Marín-León, ${ }^{1}$ Helenice Bosco de Oliveira, ${ }^{1}$ Marilisa Berti \\ de Azevedo Barros, ${ }^{1}$ Paulo Dalgalarrondo, ${ }^{2}$ Neury José Botega ${ }^{2}$
}

\begin{abstract}
Objective: To analyze the association between the socioeconomic characteristics of individuals and common mental disorders. Method: A cross-sectional survey of a representative sample of the urban population, 14 years and older, in Campinas (Brazil) ( $n=515$ ) was conducted using a multipurpose instrument that included the Self-Reporting Questionnaire (SRQ-20) to assess common mental disorders in the previous 3 months. Weighted prevalence of common mental disorders was calculated for each independent variable. Crude and adjusted prevalence ratios were estimated using Poisson regression. Results: The overall prevalence was $17 \%(95 \% \mathrm{Cl}$ 12.8-22.3), $8.9 \%$ in males and $24.4 \%$ in females. An inverse association was found between common mental disorders and the socioeconomic characteristics (schooling and employment) even after controlling for all the other variables. Higher common mental disorders prevalence was observed in those with less than 5 years of schooling (PR $=5.5$ ) and unemployed or underemployed ( $P R=2.0)$. Conclusions: As in other studies, common mental disorders were unevenly distributed; it was significantly more frequent in socially disadvantaged individuals. Specific actions to reduce inequalities in the general and mental health system should be studied.
\end{abstract}

Descriptors: Mental disorders; Social inequity; Socioeconomic survey; Serial cross-sectional study; Epidemiology

Resumo

Objetivo: Analisar a associação entre características sócioeconômicas e transtornos mentais comuns. Método: Realizou-se um inquérito epidemiológico transversal em uma amostra representativa da população $\geqslant 14$ anos de idade, residente na zona urbana de Campinas (SP), utilizando-se um instrumento que incluiu o Self-Reporting Questionnaire (SRQ-20) para avaliar transtornos mentais comuns nos últimos três meses. A prevalência ponderada de transtornos mentais comuns foi calculada para cada variável independente. Razões de prevalência bruta e ajustada foram estimadas por regressão de Poisson. Resultados: A prevalência global foi de 17\% (95\% IC 12,8-22,3), 8,9\% em homens e 24,4\% em mulheres. Observou-se uma associação inversa entre transtornos mentais comuns e características sócio-econômicas (escolaridade e emprego) mesmo após ajuste. Apresentaram maior prevalência de transtornos mentais comuns os indivíduos com menos de cinco anos de escolaridade (RP = 5,5) e os desempregados ou subempregados $(R P=2,0)$. Conclusão: Como em outros estudos, os transtornos mentais comuns estão desigualmente distribuídos, sendo mais freqüentes em indivíduos que se encontram sob pior condição socioeconômica. Deveriam ser desenvolvidas ações que pudessem reduzir as desigualdades em geral e no campo da saúde mental.

Descritores: Transtornos mentais; Iniqüidade social; Enquete socioeconômica; Estudos transversais seriados; Epidemiologia

1 Department of Preventive and Social Medicine, School of Medical Sciences, Universidade Estadual de Campinas (UNICAMP), Campinas (SP), Brazil

2 Department of Medical Psychology and Psychiatry, School of Medical Sciences, Universidade Estadual de Campinas (UNICAMP), Campinas (SP), Brazil

Financing: World Health Organization (grant M4/445/119) and Fundação de Amparo à Pesquisa do Estado de São Paulo - FAPESP (grant 02/08288-9)

Conflict of interests: None

Submitted: June 13, 2006

Accepted: November 24, 2006
Correspondence

Neury J. Botega

FCM UNICAMP, Depto de Psiquiatria

Caixa Postal 6111

13081-970 Campinas, SP, Brazil

E-mail: botega@fcm.unicamp.br 


\section{Introduction}

Common mental disorders (CMD) characterized by anxiety, depression and/or somatic complaints with no identifiable organic basis cause discomfort and frequent significant limitation of daily life activities. ${ }^{1}$ A study performed in Olinda, Brazil, used the Self-Rating Questionnaire (SRQ-20) with a cut-off score of 6 or more, revealing a 35\% CMD prevalence in a population aged 15 and older. ${ }^{2}$ In Pelotas, a study on individuals aged between 20 and 69 years with the same instrument verified $28.5 \% \mathrm{CMD}, 21 \%$ prevalence in men and $34.2 \%$ in women, which was equal to or above the cut-off score of 7 applied in men and 6 in women. ${ }^{3}$ In the State of Sao Paulo, the prevalence of CMD with a cut-off score of 8 was $17.4 \%$ in a population sample of 3,890 individuals aged 18 years and older, residing in 4 cities. $^{4}$

Published studies have indicated a higher prevalence of CMD associated with unfavorable socioeconomic conditions. ${ }^{1-4}$ However, a comparison between studies is not possible due to the diversity of social indicators used: schooling, occupation, unemployment, property, and income. ${ }^{1}$ A mental status that has previously been impaired and deteriorated by unemployment also contributes to this relationship. ${ }^{5}$ These studies present great heterogeneity regarding the diagnostic criteria, even when the instruments and cut-off scores for "case" definition are similar. ${ }^{5}$ The objective of this study was to analyze the association between the socioeconomic characteristics of individuals and CMD in a representative sample of a large urban population.

\section{Method}

This cross-sectional study was based on a survey of the Campinas population, as part of the World Health Organization's (WHO) SUPRE-MISS project - Multicentre Intervention Study on Suicidal Behavior. ${ }^{6}$ This transcultural study, which was conducted in 8 countries (Brazil, Estonia, India, Iran, China, South Africa, Sri Lanka, and Vietnam) under the supervision of the Australian Institute for Suicide Research and Prevention, Griffith University, Brisbane, Australia and the National Center for Suicide Research and Prevention of Mental III-Health, Karolinska Institute, Stockholm, Sweden, aimed at preventing suicide.

Urban residents in Campinas were randomly selected according to a stratified cluster sample. The census sectors were divided in 3 strata, according to the percentage of head of household who had attended university (high stratum more than 25\%; middle stratum 5 to $25 \%$, and low stratum less than $5 \%$ ). Ten census sectors were randomly chosen from each stratum and 20 domiciles were randomly selected from each sector. One individual aged 14 or older was randomly chosen from each of these domiciles. The selection ranged from "elite" regions, where the population had to be convinced to collaborate, to slums, where we had to work in groups with a supporting vehicle to ensure safety. Out of 538 randomly selected individuals, 515 agreed to participate, a loss of 23 individuals (4.2\%; 17 from the sector with higher schooling). ${ }^{7}$

A standardized questionnaire based on the European Parasuicide Study Interview Schedule (EPSIS) used by the WHO/EURO Multicentric Study on Suicide Behavior ${ }^{8}$ was applied in the survey. Interviewers were trained graduate students. Besides data such as socioeconomic and demographic characteristics, suicidal behavior and others, the Self-Rating Questionnaire (SRQ-20), ${ }^{9}$ validated in Brazil, ${ }^{10}$ was also incorporated in the original protocol. The SRQ-20 questions with yes/no answers referred to a period of 3 months before the interview. Scores $\geqslant 8$ on a scale zero to 20 were used as indicative of CMD. This yes/no-dichotomized variable was defined as a dependent variable.

Demographic characteristics (sex, age group, current conjugal status and children) and socioeconomic variables generally used to characterize social inequalities (schooling, annual individual income and present occupation of the interviewee) were defined as independent variables. The original 11 occupational categories were divided into 3 groups: 1 ) active - composed of formal employees, employers and freelancers; 2) inactive - composed of housewives, students and retirees; 3 ) unemployed (out of a previous job and presently looking for a job) and precariously employed.

The STATA software version 7.0 was used for statistical data analysis. Weighted CMD prevalence was calculated in accordance with independent variables. Prevalence was weighted to incorporate the different selection probabilities of sample constituents. The crude and adjusted prevalence ratios (PR) and respective 95\% confidence intervals ( $\mathrm{Cl}$ 95\%) were calculated. In order to control confounding regarding CMD prevalence, all variables with $p<0.20$ in the univariate analyses were included in a Poisson regression.

This study received the approval of the Ethics Committee, School of Medical Sciences, Universidade Estadual de Campinas, and all the interviewees were guaranteed confidentiality and signed an informed consent.

\section{Results}

An overall CMD prevalence of $17 \%$ was observed. Table 1 highlights the high prevalence of psychiatric morbidity in women, people aged 55 or older, subjects with less schooling, those with children and the unemployed or precariously employed (self-employed, without regular activity).

The multivariate analysis indicated that female sex, age 55 and over, lower schooling and unemployment/precarious employment are independently associated with CMD. Individuals with less than 5 years of schooling and between 5 to 12 years of study had, respectively, 4.57 and 4.21 times higher prevalence of CMD than those with more than 12 years of schooling. Unemployed or unstably employed individuals had twice the prevalence of CMD than active individuals.

\section{Discussion}

The 17\% CMD prevalence observed in Campinas was similar to a study conducted in 4 cities of the State of São Paulo ${ }^{4}$ but lower than in Olinda (35\%). ${ }^{2}$ This difference may probably be due to different cut-off scores and the Campinas sample being representative of the city, while the Olinda population sample was from one of the 5 administrative areas, with low income and high population density.

For comparison purposes, when the SRQ-20 cut-off score (6) used in Olinda was applied, the prevalence of CMD in Campinas was $27.5 \%$ (Cl 95\%: 21.8-34.2), 18\% (Cl 95\%: $11.8-26.4)$ in men and $36.3 \%(\mathrm{Cl} 95 \%$ : 29.5-43.7) in women; using the cut-off score applied in Pelotas resulted in a CMD prevalence in Campinas of 25.7\% (Cl 95\%: 20.132.2 ), $14.1 \%$ (Cl 95\%: 8.4-22.7) in men. An overall comparison between Campinas and Pelotas revealed lower prevalence in the male sex of Campinas (14.1\% vs. $21 \%$ ).

These CMD prevalence rates must be interpreted cautiously as the SRQ-20 is known to overestimate CMD prevalence due to high proportion of false positive cases. ${ }^{9,10}$ Three other 
Table 1 - Common mental disorders: prevalence according to demographic and socioeconomic variables

\begin{tabular}{|c|c|c|c|c|c|}
\hline Variable & $n$ & $\begin{array}{l}\% \text { Prevalence } \\
(95 \% \mathrm{Cl})\end{array}$ & $\mathbf{p}^{*}$ & $\begin{array}{l}\text { Crude PR } \\
(95 \% \mathrm{Cl})\end{array}$ & $\begin{array}{l}\text { PR adjusted for sex, age group, conjugal status, } \\
\text { children, schooling, income, occupation ( } 95 \% \mathrm{Cl})\end{array}$ \\
\hline Sex & & & 0.002 & & \\
\hline Male & 199 & $8.9(4.5-17.1)$ & & 1 & 1 \\
\hline Female & 316 & $24,4(18.9-30.9)$ & & $2.73(1.38-5.39)$ & $2.72(1.43-5.17)$ \\
\hline Total & 515 & $17.0(12.8-22.3)$ & & & \\
\hline Age group & & & 0.033 & & \\
\hline $14-24$ & 106 & $10.8(6.3-18)$ & & 1 & 1 \\
\hline $25-54$ & 272 & $18.4(13-25.4)$ & & $1.69(0.95-2.99)$ & $1.55(0.73-3.29)$ \\
\hline $55 e^{+}$ & 137 & $22.2(15.6-30.5)$ & & $2.05(1.22-3.41)$ & $1.53(0.75-3.13)$ \\
\hline Conjugal status & & & 0.172 & & \\
\hline Single & 148 & $13.6(9.1-19.8)$ & & 1 & 1 \\
\hline Married /Living together & 286 & $17.6(11.5-25.9)$ & & $1.29(0.85-1.96)$ & $0.71(0.26-1.94)$ \\
\hline Widowed/Divorced & 81 & $25.8(15.3-40.1)$ & & $1.90(1.01-3.56)$ & $0.74(0.28-1.92)$ \\
\hline Children & & & 0.015 & & \\
\hline No & 160 & $12.3(8.4-17.7)$ & & 1 & 1 \\
\hline Yes & 355 & $19.9(14.5-26,6)$ & & $1.62(1.10-2.38)$ & $1.60(0.63-4.07)$ \\
\hline Schooling & & & 0.016 & & \\
\hline$<5$ years & 200 & $21.8(15.1-30.4)$ & & $5.34(1.79-15.94)$ & $4.57(1.27-16.43)$ \\
\hline $5-12$ years & 239 & $16,5(11.1-23.8)$ & & $4.05(1.23-13.36)$ & $4.21(1.14-15.52)$ \\
\hline$>12$ years & 75 & $4.1(1.3-11.7)$ & & 1 & 1 \\
\hline Individual annual income & & & 0.079 & & \\
\hline Without income & 127 & $14.8(9.3-22.9)$ & & $1 ., 86(0.63-5.54)$ & $0,69(0,19-2,52)$ \\
\hline$<$ US $\$ 2,501$ & 188 & $23.3(15.6-33.1)$ & & $2.92(1.14-7.50)$ & $1.36(0.43-4.26)$ \\
\hline US\$2,501-10,000 & 146 & $12.0(5.6-24.0)$ & & $1.51(0.44-5.18)$ & $1.00(0.25-4.04)$ \\
\hline$>$ US $\$ 10,000$ & 54 & $7.9(3.1-18.8)$ & & 1 & 1 \\
\hline Occupation & & & 0.018 & & \\
\hline Active & 220 & $11.5(6.6-19.3)$ & & 1 & 1 \\
\hline Housewives, students, retirees & 199 & $19.3(13.4-26.9)$ & & $1.67(0.90-3.09)$ & $1.44(0.85-2.45)$ \\
\hline $\begin{array}{l}\text { Unemployed and unstable } \\
\text { employment }\end{array}$ & 95 & $26.4(17.6-37.5)$ & & $2.29(1.30-4.00)$ & $2.12(1.25-3.58)$ \\
\hline
\end{tabular}

${ }^{*} p$ value in chi-squared test of CMD prevalence for each variable

methodological limitations have to be taken into account. First, probability sampling was employed. Although, some deviations from what could be otherwise expected from a random distribution were found, as the unbalanced sex ratio, this was compensated by the weighting prevalence rates obtained. Secondly, in a post hoc analysis, we verified that the size of our sample was adequate for age range, schooling, income, employment, conjugal status, and children. Only sex with a design effect of 1.64 would have required a larger sample. Thirdly, inferences about causality are limited by the cross-sectional design and thus this study just indicates associations between the variables and CMD.

This study confirmed the findings of other authors ${ }^{1,2,4,11}$ regarding the unequal relationship between CMD prevalence and schooling, which is higher in individuals with less schooling $(<5$ years elementary school). It also confirmed that CMD decreases as schooling level increases. ${ }^{2,4}$ Probably, individuals with less schooling are usually less able to face adversities. A higher level of education favors health as it provides better job opportunities and living conditions, while illiteracy and low level of education are associated with poor living conditions that make access to treatment difficult. Patel \& Kleinman observed that literacy programs can positively influence mental health by reducing hopelessness and insecurity. ${ }^{12}$

In Pelotas and Sao Paulo, 3,4 a gradual decrease in CMD was observed with the increase in per capita income. In Olinda, this variable continued associated even after adjustment for other variables. ${ }^{2}$ In Campinas, since, differently from other studies, individual income and not family income was used, this variable was not statistically associated with CMD. The correlation index between schooling and individual income was low (0.48). Most of the interviewees in the category "without income" were students (29.1\%) and housewives (52.7\%); some of them, most probably had a better standard of life due to a higher family income. Although income was not independently associated with CMD, in the adjusted model its presence reduces in $11-14 \%$ the PR of the schooling categories.

Similarly to other studies ${ }^{1,2,13,14}$ we observed that in Campinas, employment status was inversely related to CMD prevalence: the group of unemployed or with precarious jobs had the highest prevalence of psychiatric morbidity, even when this variable was adjusted for the rest. The economic stability obtained from a stable job status ensures better living conditions, health and emotional stability. Unemployment and precarious jobs cause loss of buying power and economic insecurity that may compromise mental health. It has to be taken into account that reverse causality cannot be ruled out, people with CMD may have lower employability. In Britain, a cohort study has observed the importance of unemployment in the maintenance of CMD. ${ }^{15}$

The use of social status indicators such as schooling and job status revealed important social differences in CMD prevalence in Campinas. We suggest that mental health programs in poor socioeconomic areas of the municipality should receive larger resources for employability programs, as well as for training health teams to attend to these patients, so that this inequality is reduced with effective health care. 


\section{References}

1. Fryers T, Melzer D, Jenkins R. Social inequalities and the common mental disorders. Soc Psychiatry Psychiatr Epidemiol. 2003;38(5):229-37.

2. Ludermir AB, Melo Filho DA. Condições de vida e estrutura ocupacional associadas a transtornos mentais comuns. Rev Saude Publica. 2002;36(2):213-21.

3. Costa JS, Menezes AM, Olinto MT, Gigante DP, Macedo S, Britto MA, Fuchs SC. Prevalência de distúrbios psiquiátricos menores na cidade de Pelotas, RS. Rev Bras Epidemiol. 2002;5(2):164-73.

4. Barros MB. Transtorno Mental Comum. In: Cesar CL, editor. Saúde e condição de vida em São Paulo: inquérito multicêntrico de saúde no Estado de São Paulo. São Paulo: Faculdade de Saúde Pública, Universidade de São Paulo; 2005. p. 163-71.

5. Wiggins BD, Schofield P, Sacker A, Head J, Bartley M. Social position and minor psychiatric morbidity over time in the British Household Panel Survey 1991-1998. J Epidemiol Community Health. 2004;58(9):779-87. Erratum: J Epidemiol Community Health. 2004;58(12)1055.

6. World Health Organization. Multisite Intervention Study on Suicidal Behaviors: SUPRE-MISS. Geneva: WHO; 2002.

7. Botega NJ, Barros MB, Oliveira, HB, Dalgalarrondo P, Marín-León L. Suicidal behavior in the community: prevalence and factors associated with suicidal ideation. Rev Bras Psiquiatr. 2005;27(1):45-53.

8. Schmidtke A, Bille-Brahe U, Deleo D, Kerkhof A, Bjerke T, Crept P, Haring C, Hawton K, Lonnqvist J, Michel K, Pommereau X, Querejeta I, Phillipe I, Salander-Renberg E, Temesvary B, Wasserman D, Fricke S, Weinacker B, Sampaio-Faria JG. Attempted suicide in Europe: rates, trends and sociodemographic characteristics of suicide attempters during the period 1989-1992. Results of the WHO/ EURO Multicentre Study on Parasuicide. Acta Psychiatr Scand. 1996;93(5):327-38.

9. Harding TW, Climent CE, Diop M, Giel R, Ibrahim HH, Murthy RS, Suleiman MA, Wig NN. The WHO collaborative study on strategies for extending mental health care, II: The development of new research methods. Am J Psychiatry. 1983;140(11):1474-80.

10. Mari JJ, Williams P. A validity study of a psychiatric screening questionnaire (SRQ-20) in primary care in the city of Sao Paulo. $\mathrm{Br}$ J Psychiatry. 1986;148:23-6.

11. Rojas G, Araya R, Lewis G. Comparing sex inequalities in common affective disorders across countries: Great Britain and Chile. Soc Sci Med. 2005;60(8): 1693-703.

12. Patel V, Kleinman A. Poverty and common mental disorders in developing countries. Bull World Health Organ. 2003;81(8):609-15.

13. Ludermir AB. Associação dos transtornos mentais comuns com a informalidade das relações de trabalho. J Bras Psiquiatr. 2005;54(3): 198-204.

14. Winefield $\mathrm{AH}$, Tiggemann $\mathrm{M}$, Winefield HR. The psychological impact of unemployment and unsatisfactory employment in young men and women: longitudinal and cross-sectional data. Brit $J$ Psychol. 1991;82(Pt 4):473-86.

15. Weich S, Lewis G. Poverty, unemployment, and common mental disorders: population based cohort study. BMJ. 1998;317(7151):115-9. 